The Next Return of Encke's Comet.-In a communication to M. Flammarion, Mr. F. E. Seagrave gives the results of his calculations concerning the return of Encke's comet in I9r4. From the elements, corrected for the Jovian perturbations, it is seen that perihelion passage should take place on December 5.89 , I9I4, while the ephemeris shows that the comet should be circumpolar and near to the earth about October 27, I914; on this date its distance from us will be about 42 million kilometres $\left(26^{\circ} 2\right.$ million miles), and the comet should be of about the fourth magnitude. The period found by $\mathrm{Mr}$. Seagrave is $1204^{\circ} 800 \mathrm{r}$ days. (L'Astronomie, December.).

The Magnitude and Colour of Brooks's Comet, IgIIc.-In a note appearing in No. 4619 of the Astronomische Nachrichten, Herr Max Valier gives the magnitudes, diameters, and colours of Brooks's comet (IgII $c$ ), as observed by him during the period September 7 to November 4, 19II. Both magnitudes and colours were regularly progressive until October 2 I, the former going from $5^{\circ}$ to $x^{\circ} 8$, the latter from bluish, through blue, greenish, greenish-yellow, yellowish-red, to white; the order was then reversed in both cases.

JoHN GoodRICKe.--A portrait of John Goodricke, the astronomer who discovered the periodicity of Algol in $\mathrm{I}_{7} 8_{3}$, and suggested the accepted explanation of the star's variability, has recently been presented to the Royal Astronomical Society by Mr. C. A. Goodricke, of Hampstead. It is not generally known that John Goodricke was deaf and dumb from birth, yet, although he died in 1786 , at the early age of twentytwo, his scientific attainments had earned for him the fellowship of the Royal Society and the award of the Copley medal; his astronomical work was done at York. An interesting letter, giving the chief facts concerning Goodricke's life, appears in No. $x$, vol. Ixxii., of The Monthly Notices.

"The Companion to the Observatory."-This useful annual, for I9I3, contains practically the same matter as last year, with the various tables revised. Messrs. Denning and Lewis have revised the "Meteor Showers" and "Double Stars" sections respectively, and a welcome addition is a list of the principal star clustcrs and nebulæ. It is interesting to note, from the rage dealing with the universal time system, that every State of any importance, except Russia, now uses a standard time directly depending upon the Greenwich meridian; Russian time depends upon the Pulkowa meridian, and is $2 \mathrm{~h}$. $\mathrm{Im}$. fast on Greenwich. We remark that the editorship of The Observatory has changed hands, the new editors being Mr. F. J. M. Stratton, of Cambridge, and Mr. A. S. Eddington and Dr. S. Chapman, of Greenwich, in place of Messrs. T. Lewis and H. P. Hollis. The "Companion" is pub. lished by Taylor and Francis at is. $6 d$., and should be in the hands of every astronomical observer.

\section{DEVELOPMENTS OF NATIONAL EDUCATION}

THE papers read at the North of England Education Conference, at Nottingham, on January 2, 3 , and 4, give evidence of a growing realisation of the principal weaknesses of English public education. One of the most remarkable and significant developments in national education, and one to which considerable prominence was given in papers read by the Rev. W. Temple, headmaster of Repton School, and Mr. P. E. Matheson, New College, Oxford, respectively, is the valuable work of university level being done by the Workers' Educational Association. Mr. Temple stated that there are now more than Ioo university tutorial classes in different parts of the country, with nearly 3000 students, which have been organised and provided by this association. These classes are limited to thirty students, who undertake to attend throughout a three-years' course. The class meets once a week for twenty-four weeks during the winter session. Each student writes an essay once a fortnight. The essays are pronounced by distinguished scholars to be equal in value to the work done in Oxford by men who take a first class in the honours history school. Mr. Temple concludes from the experience of the association, that "not only is a vast amount of intellectual capacity going to waste in England at this moment for lack of opportunity," but "that men who have only had an elementary education and no secondary can none the less do work of a university type at the proper age. Of course, they have not the knowledge ... but apparently their intellectual capacity has gone on growing."

The advantages of practical and manual worl of various types in elementary schools were frequently insisted upon. Mr. Bird, superintendent of handicraft, Leicester Education Committee, criticised effectively the defects of the present methods of manual training in schools, in which so much stress is laid upon mere copying of models, and so little attention given to developing the ingenuity and originality of the boys. A suggestive criticism was made by Mrs. Ogilvie Gordon in a paper on "trade schools" upon the much-quoted Continuation Trade Schools of Munich. She stated that "a weak point in the Munich system, and in most of the Continental systems, is that there is no easy bridge by which the public elementary and trade continuation class scholar can pass into the higher raniss of his vocation and complete his studies in the polytechnic or university. The avenue to these higher courses is solely through the gymnasial high schools."

Sir William Mather, in a weighty and important paper on the cooperation of employers and education authorities, complained "of the want of aptitude and intelligence, application and interest, displayed by a considerable majority of the boys and girls coming to work direct from the elementary schools." From his experience as an employer who had for some years made attendance at evening continuation schools compulsory upon his junior employees, he strongly urged a similar course of action upon all employers of labour. In a paper upon the educational responsibilities of the employer, Councillor George Cadbury, jun., described the remarkably complete scheme of continued education (mental and physical) in operation at the Bournville Works for the junior employees. The main features of the scheme are (I) compulsory attendance at evening continuation school, with remission of fees, and the award of prizes; (2) physical exercises and swimming during the firm's time; (3) special technical and commercial classes within the worlss during working hours. J. WILSON.

THE INHERITANCE OF FECUNDITY IN FOWLS. ${ }^{1}$

THE application of Mendelian principles to the inheritance of an economically productive character of an animal has a twofold importance, viz. first, because it may be questioned whether or not it is possible to apply a Mendelian interpretation to the facts, and, secondly, the data and conclusions arrived at make it possible for others to outline a practical scheme of breeding with the view of an increased egg-production.

In the study before us, Mr. Raymond Pearl, an investigator well known by his work on the fecundity and breeding of fowls, sets forth in great detail the I ' The Mode of Inheritance of Fecundity in the Domestic Fowl.' By Raymond Pearl, Journ. Exp. Zool., 1912, pp. $153-268$. 